\title{
Vida Cotidiana, História e Movimentos Sociais
}

José Maurício Domingues

\section{O PROBLEMA}

relação entre a vida cotidiana e a história não tem sido fácil de
compreender. Do ponto de vista mesmo das concepções e do
imaginário modernos as coisas têm sido bastante problemáticas. Na
literatura e na arte da narrativa em geral, esse tem sido um problema
candente desde pelo menos o século XIX. Na época de Goethe, ele sur-
giu no que se convencionou chamar de "crise do romance", quando
este tendia a perder seu caráter épico - histórico -, não lhe sobrando
nada mais do que mergulhar na banalidade da vida cotidiana, pro-
blema que se arrastou pelo século seguinte, encontrando soluções
diversas, como a que Brecht buscou oferecer retornando de forma
muito transformada à epicidade das narrativas pré-modernas (ver
Bornheim, 1992). Deve-se levar em conta que se o problema não era
anteriormente desconhecido, a modernidade emprestou-lhe centrali-
dade inédita, uma vez que a dignidade individual do homem comum
se afirma precisamente nesse espaço indiferenciado, por todos com-
partilhado, que não é senão aquele da cotidianidade (Taylor, 1989).
Como foi que as ciências sociais trataram desse problema, qual seja,
do enlace da vida cotidiana com a história? Como em particular a so-

DADOS - Revista de Ciências Sociais, Rio de Janeiro, Vol. 46, nº3, 2003, pp. 461 a 490. 
ciologia buscou enfrentá-lo? Terão sido as suas soluções satisfatórias? Em particular, como se articulam mudança social em larga escala e vida cotidiana? Mais ainda, como pensar essa temática no período atual, no que tange à globalização que se aprofunda e aos movimentos que, criticamente, a ela se associam?

Este artigo tentará dar conta deste tema em três etapas. Primeiramente, situarei a noção de vida cotidiana em uma de suas principais expressões na sociologia, como forma preliminar de enfocar a questão. Em seguida, debruçar-me-ei sobre a fenomenologia, em particular sobre seu conceito de "horizonte", que fornece, creio, uma das chaves para a solução dessa problemática teórica. Finalmente, buscarei relacionar essa discussão mais diretamente ao campo teórico dos sistemas sociais, principalmente à teoria dos movimentos sociais, uma vez que estes têm sido vistos na modernidade como os indutores da mudança histórica por excelência. Esta não deve ser pensada como único aspecto da história, que é também em larga medida reprodução do existente, mas na modernidade adquiriu grande centralidade, assumindo particular dimensão com a globalização. Assim, em especial os movimentos do atual período de globalização acentuada, mas também, nas mesmas coordenadas, processos mais amplos que assim se desenvolvem, receberão atenção ao cabo deste percurso. A teoria da subjetividade coletiva, que venho ao longo dos últimos anos desenvolvendo, fornece as amarras gerais do argumento aqui articulado.

\section{GOFFMAN E A ABRANGÊNCIA DA VIDA COTIDIANA}

Uma das sociologias mais influentes no que se refere à vida cotidiana foi sem dúvida a de Goffman. Ele juntou vários campos disciplinares em sua tentativa de entender as interações sociais, incluindo é claro a psicologia social pragmatista de Mead e o interacionismo simbólico de Blumer, assim como a etologia e a fenomenologia. Seus resultados teóricos foram também em certa medida múltiplos. No entanto, suas teses encontram-se imbricadas com estudos mais específicos e ele próprio em geral ou não as percebeu de forma completa ou não se interessou por explicitá-las. Isso não obstante, pode-se dizer que, do ponto de vista teórico mais amplo, foi a "ordem da interação" que mereceu a sua atenção (Goffman, 1983 - na verdade seu único texto de síntese conceitual). Não pretendo aqui explorar as diversas expressões de sua obra. Para os interesses deste estudo, basta assinalar dois elementos. 
Primeiro, que todas as interações implicam a constituição de um espaço-tempo específico, concreto. Em outras palavras, que o tempo e o espaço social não devem ser, se nos debruçamos sobre a sociologia de Goffman, entendidos em sentido newtoniano (hobbesiano no que tange às ciências sociais). A tradição moderna original pensou o tempo e o espaço como abstratos e homogêneos, como meras variáveis paramétricas dentro das quais se desenrolava a ação humana. Goffman repele praticamente esta visão, apesar de jamais discuti-la, e nos oferece uma perspectiva do espaço-tempo como parte intrínseca dos sistemas sociais, assumindo sempre um caráter heterogêneo (ver Giddens, 1987, que desenvolve com precisão esse ponto de vista). Pode-se avançar além disso e, em concordância com ele, pensar as dimensões simbólica, material (a do intercâmbio com a natureza) e do poder como analiticamente paralelas e imbricadas com a dimensão espaço-temporal dos sistemas sociais, das subjetividades coletivas elas, assim como os indivíduos, constituídas nos processos de interação social (Domingues, 1995a; 1995b, cap. 8).

Além disso, é importante assinalar a abrangência do conceito de vida cotidiana em Goffman. Assim como Heller (1984:6), para quem a vida cotidiana diz respeito ao "meio imediato" das pessoas - plebeus ou reis, pouco importa -, Goffman entende-a como perpassando tudo, como constituindo a base da vida social, em quaisquer de seus aspectos e esferas. Ele trata, portanto, de todos os momentos da vida social, e não apenas de seus instantes por assim dizer privilegiados (Joseph, 1998). Isso é importante, nos quadros deste artigo, em particular por deixar claro que não só a historicidade da vida cotidiana é um dado que deve prender a nossa atenção, mas igualmente por permitir uma articulação direta e imediata entre vida cotidiana e história. Em outras palavras, as diversas conformações das "subjetividades coletivas" atravessam a vida cotidiana e projetam-se, em maior ou menor medida, na direção de tecer todo o curso da vida social, que por si mesma possui um caráter histórico, como dimensão dos sistemas sociais mais amplos, sejam eles "sociedades" ou civilizações, em si e em seu encadeamento processual. Imbricam-se e sobrepõem-se, portanto, diversos e até certo ponto díspares espaços-tempo sociais. Assim, para remeter aos estudos do próprio Goffman (1956; 1963), a representação do "eu" na vida cotidiana, seja por parte de funcionários, médicos ou presidentes da república, inclui a conformação de regiões abertas ou fechadas, de acesso amplo ou restrito. Também o controle 
da atenção civil em público atravessa desde encontros na rua, por pessoas comuns, até o que se passa em cerimônias oficiais importantes, nas quais decisões ou rituais cruciais para o desdobramento da história são encetados, os quais articulam um espaço-tempo que, como dimensão de um sistema social extremamente abrangente, não se reduz à interação específica (como de resto nenhuma delas o faz, pois se imbrica com processos interativos mais amplos, sendo parte deles e os constituindo entre indivíduos e subjetividades coletivas).

Para que se compreenda melhor a significação desse passo, é necessário que avancemos um pouco mais. Em particular, o conceito de "horizonte" ser-nos-á de grande valia. Para entendê-lo em profundidade, faz-se necessário, contudo, tratar da fenomenologia.

\section{A FENOMENOLOGIA E O CONCEITO DE "HORIZONTE"}

A fenomenologia é a escola de sociologia e filosofia que mais profundamente estudou a vida cotidiana. Os autores fenomenológicos forjaram uma série de conceitos para dar conta dessa dimensão. O de "horizonte" permite-nos, dentre tantos confeccionados, ligar o cotidiano à história. Porém, é preciso inseri-lo na teia conceitual mais vasta forjada por aqueles autores para que possamos compreendê-lo. Segundo a sociologia fenomenológica, vivemos em um "mundo da vida" no qual impera a "atitude natural" - implicando um não-questionamento dos fenômenos sociais, que se toma como dados. Esse mundo da vida é por excelência o mundo cotidiano, de "experiências" ou "vivências"1 de proximidade, no qual se distinguem várias "províncias de significado", todas entretanto regidas pela atitude natural, por interesses pragmáticos e pelas tipificações dos papéis sociais desempenhados pelos agentes com que interagimos. "Estoques de conhecimento" que derivam de situações biográficas particulares e dizem respeito a cada uma daquelas províncias são incorporados pelos atores ao longo de suas vidas (Schutz, 1967; 1973e; 1975).

No mundo da vida, cada objeto, e aí se incluem atores sociais também, nunca é percebido de forma isolada, mas dentro de um horizonte caracterizado por sua "familiaridade típica e pré-conhecimento" (idem, 1973c:279). E cada dimensão, de proximidade ou distância no tempo e no espaço, assim como de intimidade e anonimidade, tem sua "estrutura de horizonte" (idem, 1973g:148). Entretanto, esse horizonte está sempre "em fluxo", e cada aproximação o faz mais preciso (idem, 
1973c:279). O problema é que, conquanto perceba a questão do futuro e, por vezes, inclusive, ponha o tema da criatividade em pauta, a fenomenologia em suas correntes mais tradicionais privilegia fortemente a questão da memória e do passado tal qual depositado em experiências incorporadas pelo sujeito. É nessas coordenadas que se insere o conceito de "horizonte".

Em Husserl, ele pode ser visto da seguinte forma, com mais detalhes ${ }^{2}$. Toda vivência, ele afirma, tem seu horizonte próprio, relativamente indeterminado, de possibilidades, que se abre a uma determinação crescente, nos quadros de vivências reais (Husserl, 1964, § 8:27). Segundo ele, cada uma dessas vivências tem um "horizonte" variável em sua mudança de relações de consciência e na mudança de sua própria fase de fluxo - um horizonte que remete, indica, a partir de si próprio, potencialidades pertencentes à consciência. E ele junta um exemplo a isso: a cada observação externa pertence a remissão dos lados realmente observados do objeto de observação ao que é significado conjuntamente com eles, ainda não observados, mas sim apenas em expectativa e primeiramente em lados antecipados de um vazio não propriamente visto - como aquilo que então virá a ser observável, uma "protenção" permanente, a qual, com cada fase da observação, adquire novo significado. Além disso, a observação tem múltiplas "possibilidades", dependendo de como nos relacionamos com o objeto, no caso exemplificado, de como o olhamos, o que se estende inclusive aos processos de "rememoração" (Widererinnerung). E além disso, ele continua, pertence a cada observação sempre um "horizonte passado" como potencialidade de despertar uma nova recordação e a cada uma desta como horizonte a mediata intencionalidade contínua de possíveis rememorações até respectivamente reais observações no presente. Com isso,

"[...] joga-se sobretudo com essas possibilidades, um eu posso e eu faço
assim como eu posso de outra maneira do que eu faço-de resto sem prejuí-
zo das possíveis inibições sempre abertas, assim como daquela liber-
dade. Os horizontes são potencialidades traçadas de antemão" (idem,
1973, § 19:82).

Pode-se dizer também que é possível perguntar, expor, destampar as potencialidades da vida da consciência em relação a cada horizonte. Todavia, mesmo com isso se expõe sempre apenas no cogito real um certo grau da denotação do sentido objetivo implicitamente significa- 
do. Este, "o cogitante como cogitato", nunca aparece como um dado pronto manifestado. Ele se esclarece antes mediante essa exposição do horizonte e do horizonte sempre novamente despertado. O próprio "indício" é realmente o tempo todo "fragmentário" (unvolkommen), porém em sua indefinição de uma estrutura da definibilidade. Isso se encontra assim em mutação e atualização permanente a partir da própria relação entre experiência e "representação" antecipada (idem, 1973, § 19:82-83). Ademais, no mundo imaginário, diferentemente do real, as coisas permanecem abertas; se o horizonte da percepção tende à definição progressiva, a imaginação, ao contrário, implica um "horizonte obscuro", que por princípio deve assim permanecer (idem, 1964, § 40:200).

Objetos possuem a um só tempo um horizonte interno e outro externo, relacional com o mundo. Assim, toda vivência de uma coisa singular tem seu horizonte interno - que Husserl designa como a "indução" que pertence a toda experiência como indução originária, como antecipação das qualidades do objeto. Mas há também o horizonte externo, que fica para além do objeto, e se refere às coisas que se dão ao mesmo tempo que ele. Esse horizonte externo é aberto e infinito. Revelando bem claramente o quanto seu projeto radica mais em um entendimento da "contemplação" do que na "ação" - o que se mostra evidentemente limitado para uma perspectiva sociológica, mas é perfeitamente compreensível nos quadros da filosofia da consciência que a fenomenologia culmina -, ele observa ainda que aquela se articula precisamente àqueles dois tipos de horizonte (idem, 1964, § 8:28 e § 22:114-116; ver também Schutz, 1973b:108).

Além disso, embora Husserl mostre que entende de alguma forma a noção de horizonte como incluindo uma possibilidade de mudança, e Schutz indique que objetos individuais dependem ao fim e ao cabo de novas percepções específicas (Schutz, 1973c:282; 1973f:296), no fundamental esse conceito remete para eles ao passado, a "experiências" já realizadas e à expectativa de sua repetição - ainda que nos quadros de "expectativas de protensão" (idem, 1973d:79; 1973c:285). Esta se baseia fundamentalmente em um "estoque de experiência" (store of experience) e tem como circunferência um "horizonte de interesse" (idem, 1973a:136). Segundo essa perspectiva,

“O mundo factual de nossa experiência [...] é experimentado desde o princípio como típico. Objetos são experimentados como árvores, ani- 
mais e coisas semelhantes, mais especificamente como carvalhos, pinheiros, bordos, ou cascavéis, pardais, cães. Esta mesa que percebo agora se caracteriza como algo reconhecido e, todavia, novo. O que é experimentado como novo já é conhecido no sentido de que relembra coisas similares ou iguais percebidas anteriormente. Mas o que foi absorvido antes em sua tipicalidade carrega consigo um horizonte de experiência possível com referências correspondentes de familiaridade, isto é, como uma série de características típicas ainda não experimentadas mas que se espera serem potencialmente experimentadas" (idem, 1973c:281).

Essas teses são verdadeiras também nos quadros da obra de Habermas. Segundo ele, o mundo da vida - que inclui a esfera privada e a esfera pública - funciona como um reservatório de entendimentos e convencimentos não problemáticos, os quais podem ser contudo problematizados de forma consensual quando se tornam relevantes para uma situação. São assim "tematizados" como "conhecimento" (Wissen). Entretanto, as fronteiras do mundo da vida não se deixam transcender; dessa forma, ele se protege contra uma "revisão total" (Habermas, 1988, vol. 2:201,513). Qual a relação do conceito de horizonte com isso? Para Habermas, a "situação de ação" oferece aos participantes o centro de seu mundo da vida. Eles têm um horizonte móvel, o qual remete à "complexidade do mundo da vida". Em certa medida, o mundo da vida está sempre presente, fornecendo o "pano de fundo" para cenas reais, mas pode, ao tornar-se um elemento da situação, perder a sua "trivialidade e inquestionável solidez" (idem:188).

Um dos problemas centrais que aqui se coloca diz respeito ao fato de que, para as correntes tradicionais da fenomenologia, mas também nos quadros da obra de Habermas, como a discussão acima deixa claro, o "mundo da vida" possui uma estrutura pré-reflexiva, que se toma como dada, implicando a repetição das coisas tal qual as conhecíamos de antemão. É o que Schutz, como já mencionado, chama de "atitude natural", e que Gadamer (1990), de certo ponto de vista talvez nem tão estrito, recupera mediante o conceito de "tradição" e a noção de "pré-conceito" (através dos quais se pode realizar a compreensão hermenêutica e a "fusão" de distintos horizontes). Por outro lado, a noção de ação também supõe ou mera experiência ou "vivência" (erlebnis), sobre a qual nos é vedado pensar, ou a sua reorganização aí sim reflexiva, de modo contemplativo, por meio da qual se atribuiu sentido à ação - a uma ação passada, todavia, a qual já se acha con- 
cluída (Husserl, 1973, § 15:72-75; Schutz, 1967:15-25, 35-37 e 56 e ss.). Habermas deixa de lado claramente uma concepção individualista do mundo da vida e ataca a filosofia da consciência, entretecendo o conceito de "mundo da vida" fortemente com uma concepção que, por meio de uma pragmática do discurso, visa a intersubjetividade dos participantes na constituição do que seria para ele uma das esferas principais e primordiais da sociedade. Vários problemas, contudo, permanecem, não só do ponto de vista dessa concepção do mundo da vida como pré-reflexivo, mas também da relação do conceito de horizonte com a história, problemas que, creio, na verdade, possuem forte vínculo. Embora eu não possa desenvolver o ponto em profundidade aqui, vale frisar que devemos pensar a temática dos horizontes tendo em mente uma concepção mais ampla de reflexividade, incluindo seus aspectos não identitários, práticos e sistemáticos (os únicos que Husserl, Schutz e Habermas - mas não Sartre - reconhecem). Assim, não só a contemplação se mescla à ação e à prática, como o pensamento se apresenta em sua complexidade e heterogeneidade, sem se opor à vivência, à experiência ou assumir caráter eminentemente racional ${ }^{3}$.

Antes de seguir adiante, todavia, aprofundemos a potencialidade do conceito de horizonte e como ele foi trabalhado por outros autores.

De início, deve-se dizer que a vantagem do conceito de horizonte é que ele nos permite trabalhar sem supor uma ruptura entre vida cotidiana e história. Dependendo do horizonte disponível aos indivíduos e subjetividades coletivas, um tipo de atividade pode ser privilegiado e não outro: um continuum em que tudo é vida cotidiana e, por outro lado, se conecta à reprodução ou à mudança histórica impõe-se. Em outras palavras, e para recuperar as questões postas por Goffman, com o conceito de horizonte os espaços-tempo da vida cotidiana e da história são entrelaçados. Entretanto, o caráter individualista do conceito de horizonte precisa ser revisto. Decerto, ele inclui memórias individuais, idiossincráticas - e este é de fato um dos elementos interessantes do conceito fenomenológico de memória, em oposição à principal tradição sociológica durkheimiana, parsoniana e bourdieusiana. Mas os processos interativos em que memórias são criadas e compartilhadas, principalmente em termos de sistemas sociais mais ou menos permanentes, isto é, subjetividades coletivas de memória e, portanto, de horizonte compartilhados, ainda que incompletamente, 
devem ser também levados em conta centralmente ao se discutir esse conceito.

A articulação entre o conceito de cotidiano e história pode ser aprofundada ao recorrermos a Heidegger. Para ele, a "cotidianidade" (Alltäglichkeit) oferece o "horizonte" mais próximo do Ser-aí, no qual ele, ademais, se comporta de acordo com a sua queda na "inautenticidade". A história (Geschichte) fornece, por outro lado, um horizonte mais amplo e coletivo ao Ser-aí (Heidegger, 1993, § 9:42 e ss., §§ 28-38:130 e ss., e $§ 71: 370$ e ss.). Isso só é possível, pode-se dizer (e embora Heidegger não explicite a questão isso permanece, creio, como um subentendido), uma vez que o Ser-aí "não é temporal porque 'está' na história, senão que ele ao contrário existe historicamente e pode existir porque no fundamento de seu ser ele é temporal" (idem, § 72:376). Sartre (1985, t. I:75-77) amplia um pouco esse foco ao recusar uma idéia absoluta de alienação - pois a liberdade do sujeito sempre existe em alguma medida - e remeter o "projeto" individual ao "campo dos possíveis". Assim, o indivíduo objetiva-se e contribui para fazer história, transformando o mundo ou reproduzindo-o, mesmo que isso implique um largo espectro de conseqüências não intencionais, em qualquer das duas direções. Deve-se notar, contudo, que, embora Heidegger tenha implícita uma continuidade entre cotidiano e história, ele não examina os mecanismos através dos quais isso se processa, simplesmente tomando a solução como dada. Por seu turno Sartre (idem, Partes I e II, passim) busca operar uma junção mais direta entre os dois planos mediante conceitos como o de coletividades "seriais" (reificadas) que ele opõe à espontaneidade e à liberdade (criatividade) individuais e coletivas em fluxo. Sua solução permanece ainda assim insuficiente, pois está longe de oferecer seja uma junção adequada entre cotidiano e história, seja uma teoria mais precisa dos movimentos sociais. Voltarei a isto mais adiante.

Porém, há um outro elemento da fenomenologia, que comecei a criticar acima, que precisa ser revisto. Isso diz respeito à própria concentração dessa escola, ao falar de cotidiano ou história, na idéia de memória e experiência, o que se expressa nos conceitos de "atitude natural", pré-reflexiva ou "tradição" - este definitivamente um conceito questionado na teoria social contemporânea, o que deve ser o caso também daqueles outros dois. Tem-se aqui uma perspectiva da vida social potencialmente muito conservadora e que de resto falsifica a própria experiência da modernidade. A rigor não foi apenas a feno- 
menologia que cometeu esse erro. Vemos autores como Weber (1980:1 e ss. e 130 e ss.; ver também Domingues, 1999, cap. 2), por exemplo, atribuir às sociedades tradicionais - mediante sua discussão do conceito de ação tradicional inclusive - uma recusa à reflexividade, à mudança, à tematização da vida social, de seus valores e normas, práticas e instituições. Mais ainda: somente aos líderes carismáticos estaria reservada a capacidade de abrir o horizonte histórico (termos, observe-se, que ele não utiliza): às massas apenas o seguidismo sem reflexividade estaria reservado. Weber concentrou seus estudos no surgimento das grandes "religiões mundiais" ao analisar os movimentos sociais. Não é completamente claro como ele entenderia os movimentos sociais modernos, como o socialismo e o feminismo, sobre os quais escreveu pouquíssimo, se levamos em conta seus interesses e vasta produção.

Possivelmente como uma alternativa a isso, Koselleck - e em contraposição crucial à tradição fenomenológica, mas em direto diálogo com ela, decerto - propôs uma separação conceitual para o estudo da história que pode ser tida como decisiva para equacionar essa questão. Como herança problemática, destaque-se que ele se prende totalmente a uma contraposição entre sociedades "tradicionais" e "modernas". Isto, não obstante a limitação que gera, tem como contrapartida uma avançada compreensão da concepção de história e do movimento desta última. Assim, ele distingue entre "espaço de experiência" e "horizonte de expectativa", embora cada um dos elementos do par careça do outro, sem poder existir em completa autonomia. Além disso, deve-se dizer preliminarmente que eles implicam uma condição "antropológica" da espécie, pois se encontram em qualquer circunstância histórica, relacionando o passado e o futuro. O presente os articula, conquanto a experiência convirja para um foco e a expectativa se abra para uma "infinidade de extensões temporais" (Koselleck, 1985a:270-272). É interessante reproduzir a definição desses termos em Koselleck:

"[...] a experiência é o presente passado, cujos eventos foram incorporados e podem ser lembrados. Dentro da experiência se inclui uma reformulação racional, junto com formas inconscientes de conduta que não precisam estar presentes conscientemente. Há também um elemento da experiência alheia contido e preservado, e transmitido pelas gerações e instituições [...]. De modo similar com a expectativa: a um tempo específico de cada um e interpessoal, a expectativa tem lugar 
no hoje; é o futuro feito presente; dirige-se ao não ainda experimentado, àquilo que deve ser revelado. Esperança e medo, anseios e desejos, preocupação e análise racional, abertura receptiva e curiosidade: tudo entra na expectativa e a constitui" (idem:272).

Ele nota também que as expectativas podem mudar a experiência, mas somente novas experiências são surpreendentes. Elas excedem os limites da experiência prévia. É essa relação dinâmica entre espaço de experiência e horizonte de expectativa que gera a história enquanto tal, segundo Koselleck (idem:275).

É fundamental perceber ainda que a modernidade alterou profundamente a relação entre essas duas categorias, dando muito mais peso ao horizonte de expectativa, embora mesmo em sociedades "tradicionais" diferenças entre estratos sociais, com freqüência, implicassem também uma relação distinta entre essas duas dimensões da história (idem:276 e ss.). Assim, a modernidade (Neuzeit) conjurou um horizonte de "constante surpresa", rompendo com uma concepção circular da história. Perdia-se com isso a exemplaridade da história, e ela passava a ter de ser escrita em sua processualidade; o futuro - como enigma - tomava vulto perante o passado e inclusive o presente, e o movimento de mudança da sociedade assumia o centro da cena. Essa mudança de perspectiva começou entre os intelectuais, porém logo o conceito de "tempo" e a temporalização da vida social penetraram fundo nas visões ligadas à vida cotidiana (idem, 1985b:253-254). Os diversos "ismos" que caracterizaram e vêm caracterizando os movimentos sociais e as políticas desde o século XVIII (republicanismo, liberalismo, socialismo, comunismo, conservadorismo - após os quais se poderia acrescentar outros, alguns mais recentes, como o feminismo, o ecologismo etc.), bem como as mudanças, em sentido processual, na significação de termos como "revolução" ou "emancipação", expressam essa profunda temporalização da concepção moderna da vida social (idem:262).

Sem dúvida, concepções teleológicas da história, como as que vieram embutidas em perspectivas ilustradas (cf. Voltaire, Kant, Hegel), no marxismo ou no neoliberalismo, implicavam retornos a épocas de ouro e trajetórias preestabelecidas, mediante um racionalismo determinista e da filosofia da história (Laclau e Mouffe, 1990; Domingues, 1999, caps. 4 e 7). Pode-se sugerir, porém, que, ao propor um horizonte fechado, elas se encontravam e se encontram em tensão forte com 
uma concepção de história como horizonte aberto de desenvolvimento que a própria modernidade também ofereceu. Uma vez que se assuma um horizonte de expectativas contingente e mutável, a modernidade apresenta-se como um processo em fluxo, sem fins predeterminados, capaz, inclusive, de auto-superação. Para aprofundar essa questão, cumpre discutir quais são as bases e como a realização dessa nova concepção de história se concretiza na modernidade enquanto tal e em sua estrutura básica cotidiana.

Antes de fazê-lo, contudo, vale assinalar uma questão a mais, retomando uma das distinções da fenomenologia quanto à apresentação dos objetos, tal qual introduzida acima. Com ela em mente, é razoável dizer que os movimentos de que fala Koselleck têm um espaço de experiência e um horizonte de expectativas que devem ser lançados a um só tempo em dois planos distintos, podendo-se falar mesmo de dois espaços e de dois horizontes: um, interno, que diz respeito aos processos auto-referidos do movimento, a suas articulações endógenas e, é claro, a seu enraizamento na vida dos indivíduos e grupos que o compõem; o outro, externo, que aponta para os processos sociais mais amplos, para as perspectivas do impacto do movimento na formação social inclusiva.

\section{MODERNIDADE E MOVIMENTOS SOCIAIS}

Com freqüência, na modernidade os movimentos sociais têm sido vistos como os portadores da historicidade. É o que observamos com a proliferação de "ismos" a que se refere Koselleck. Entre os teóricos sociais contemporâneos, Touraine (1984) foi um dos que mais diretamente afirmou esse ponto de vista: a disputa pela "historicidade", isto é, a direção do desenvolvimento da sociedade a partir de um campo compartilhado por coletividades antagonistas, seria o que caracterizaria o "retorno do ator" representado pelos "novos movimentos sociais" que proliferaram na esteira do que ele viu como a crise do movimento operário a partir dos anos 80 . Ao restringir o alcance e emprestar um cunho contingente a essa historicidade, Touraine contudo alterava alguns aspectos fundamentais do finalismo com que anteriormente se pensava o papel desses movimentos, segundo alguns os "dessacralizando" (Alexander, 1998).

De fato, creio haver bastante sentido na postulação, implícita ou explícita, de que os movimentos sociais são os principais portadores da 
mudança histórica. Todavia, seria preciso pensá-la de forma mais ampla. Na verdade, a mudança histórica articula-se de maneiras mais sutis à vida cotidiana; os próprios movimentos sociais devem ter inclusive sua ligação com essa dimensão assinalada. Em suma, são duas dimensões espaço-temporais que se imbricam e produzem. A tentativa de entender como isso se dá é o que nos ocupará adiante. Antes disso, todavia, seria conveniente entender o porquê de a mudança como questão e como projeto haver se tornado tema tão candente, e de modo perene, na civilização moderna, o que deriva de transformações muito profundas da própria cotidianidade.

Nisso que alguns chamam de "sociedade de movimento", dois processos bastante concretos parecem ter sido fundamentais: a emergência dos Estados-nação modernos, assim como de uma economia capitalista (transnacional) (Tarrow, 1994:191). Se estes são os dois principais eixos sobre os quais essas mudanças se estruturam, é mister articular conceitualmente tais categorias com mais precisão de modo a podermos compreender melhor os mecanismos subjacentes às alterações no conceito de espaço-tempo social e à dinâmica histórica que eles implicam.

Primeiramente, isso deve ser feito mediante o conceito de "desencai$\mathrm{xe}^{\prime \prime}$, que precisamos remeter aos planos individual e coletivo. Indivíduos e coletividades são arrancados de seus contextos imediatos de existência, dos contextos de práticas mais repetitivas, de horizontes menos móveis que somente a longo prazo tendem a mudar, de condições sociais em que o peso das memórias é maior do que aquele que a produtividade da criatividade individual e social pode gerar. O Estado-nação e a economia capitalista fazem esse milagre - de onde, aliás, Marx retirou a expressão de que "tudo que é sólido se dissolve no ar" para retratar o caráter de revolução permanente da modernidade. Por outro lado, reencaixes individuais e coletivos são realizados incessantemente, de formas mais abstratas (como aquele que é fornecido pela cidadania) ou mais concretas e específicas, formas que tendem contudo a caducar com velocidade cada vez maior em função do aprofundamento daqueles processos de desencaixe impostos pelo desenvolvimento capitalista e pela globalização mais radical das últimas décadas e da aceleração do ritmo da modernidade daí decorrente (ver Domingues, 2002b, caps. 1-4). 
Sem dúvida, é necessário levar em conta a herança da modernidade, no que tange à concepção de história que veio se desenhando pelo menos desde os primórdios do cristianismo e que apontava para um horizonte móvel, o qual deveria ser um dia alcançado e no qual se realizariam os desígnios da espécie humana sobre a face da terra e mesmo para além dela - e que implicava a transcendência de uma condição imperfeita da espécie. A liberdade na modernidade veio a ser o valor mediante o qual isto se tornava possível e, ao mesmo tempo, o telos que se punha para esse desenvolvimento teleológico (idem, cap. 2). É correto dizer que, em termos de valores, a liberdade vem se pondo no centro do horizonte moderno, que fornece por seu turno um dos elementos constitutivos de seu imaginário. É a partir dele que um fim e sua absoluta abertura podem ser simultaneamente afirmados, se, é claro, não se definem as formas societárias específicas mediante as quais isso deve ocorrer.

Os movimentos sociais modernos respondem exatamente a esses imperativos: a uma visão da história como aberta, mas até bem recentemente como calcada em uma meta a ser atingida; e à necessidade de realizar a transcendência das condições sociais imperfeitas em que nos encontramos e nas quais a liberdade (e a igualdade e a solidariedade) se vê manietada devido precisamente a essas limitações. Aqui não é o local para aprofundar esse tema, que reputo de todo modo central para a compreensão do imaginário e das instituições modernas. Basta enfatizar que a difusão dos movimentos sociais e políticos na modernidade é fruto dessa liberdade ampliada e da busca de sua ampliação (embora crescentemente questões relativas à dominação, de certas coletividades sobre outras e da espécie sobre a natureza, o outro lado fundamental da modernidade, tenham vindo para a frente da cena). Por conta desses processos sociais ligados aos desencaixes e reencaixes modernos e da concepção de história herdada pela modernidade, a qual contudo acaba, graças às novas e particulares condições sociais, se radicalizando, podemos mesmo falar de uma "sociedade de movimento", embora seja discutível em que medida cabe falar de uma expansão dos movimentos sociais mais recentemente, uma vez que os dados sobre o tema são algo contraditórios (Meyer e Tarrow, 1998).

Contra o argumento de Olson, que pretende haver um problema de "ação coletiva" para a mobilização social - em organizações, na verdade - devido a desincentivos à ação dos indivíduos, Tarrow (1994:16 
e ss. e, esp., 23) assinala que o problema é social antes que individual: os movimentos seriam então produzidos "quando as oportunidades políticas se ampliam, quando elas demonstram a existência de aliados e quando revelam a vulnerabilidade dos oponentes". Assim, seus organizadores tornam-se "pontos focais" que "transformam oportunidades externas, convenções e recursos em movimentos", na medida também que "repertórios de contestação, redes sociais e quadros culturais diminuem os custos de juntar as pessoas".

Ele me parece estar absolutamente correto - a despeito do elemento utilitarista pouco elaborado, derivado da teoria da escolha racional e presente em seu argumento - ao fazer essas afirmações e sintetizar várias abordagens da teoria dos movimentos sociais contemporâneos. Todavia, deve-se assinalar também que são aqueles processos sociais mais amplos que subjazem a esses imperativos e possibilidades de mobilização social. São eles que, como veremos, estão na base de processos mais amplos de mobilização social, não obstante o caráter distinto que elas assumem ${ }^{4}$.

\section{DESCENTRAMENTO, MUDANÇA HISTÓRICA E GLOBALIZAÇÃO}

Faz sentido, portanto, emprestar lugar de destaque aos movimentos sociais ao pensarmos a mudança social e a história, em particular na modernidade. Mas este não deve ser o único caso em que os sistemas sociais são vistos como produtores de história. É claro, indivíduos e sistemas sociais menores, mais estáveis ou efêmeros, decerto contribuem para a mudança e a reprodução históricas, seja por meio de desejos e projetos explícitos, seja a partir de conseqüências não intencionais da ação e do movimento que indivíduos e coletividades produzem ao perseguirem suas metas, por vezes inclusive em oposição a elas. Falo, contudo, de algo mais específico e talvez intermediário entre esses dois planos: o dos movimentos sociais, que se organizam com propósitos mais explícitos, e o da vida estritamente cotidiana de indivíduos e subjetividades coletivas.

Qualquer destes planos, contudo, implica hoje fortemente um plano macro que, com mais ou menos variações, atingiu a esfera global da espécie, que conforma o sistema social até o momento mais inclusivo possível (pelo menos até que a espécie colonize outros planetas). Assim, ele abarca todas as interações possíveis dos indivíduos e coletividades, seja face a face, seja a distância (ver Giddens, 1990:64). Um 
novo, muito amplo, horizonte firmou-se, como Luhmann (1991) percebeu em sua leitura sistêmica da fenomenologia de Husserl: o da "sociedade global". Isto não quer dizer que todas ou a maioria das interações sociais sejam conduzidas no plano global, porém sim que este se põe hoje sempre como uma possibilidade. No plano individual realmente laços fortes podem ser tecidos na ausência física das pessoas, ou ao menos ser mantidos, dando continuidade a relações que se iniciaram em termos de co-presença. Podemos inclusive falar do estabelecimento de um tipo específico de "intimidade a distância", mediada por instrumentos como o telefone, a internet e o correio eletrônico (Rocha, 2000).

Entretanto, quando falamos em processos mais amplos, de eficácia social mais profunda, a mudança social parece depender de relações mais imediatas e não apenas daquelas mediadas por meios técnicos que comprimiriam o espaço-tempo, ainda que estes tenham papel importante a cumprir. Mesmo no que diz respeito às interações individuais, o transbordamento e a mistura de relações face a face sói ocorrer (p. ex., Giddens, 1990:80 e ss.). Entretanto, sobretudo as interações a distância parecem ser incapazes de sustentar em particular o estabelecimento e a continuidade dos movimentos sociais, que dependem no plano global assim como no nacional e o local de "encaixes" mais densos do que elas podem proporcionar. É isso o que veremos em breve. Antes, precisamos discutir a questão do centramento dos movimentos sociais.

Se recorremos a uma tipologia do grau de centramento dos sistemas sociais - que neste texto se equivalem conceitualmente a subjetividades coletivas -, eles não aparecem decerto como aqueles que ocupam o topo da escala. Levadas em conta as duas variáveis que informam essa tipologia - identidade, isto é, autoconsciência, e organização, isto é, a capacidade de agir coordenadamente -, "organizações formais", tais como definidas classicamente pela sociologia, apresentam grau de centramento superior ao dos movimentos sociais (Domingues, 1995b: esp. 152 e ss.). Ainda assim, o grau de centramento dos movimentos sociais mostra-se bastante elevado, e sua capacidade de porem-se metas, se reconhecerem como movimentos e coordenarem sua ação, não poderia ser subestimada. Isto é verdade para muitos deles, sobretudo aqueles que emergiram durante o século XIX e atravessaram o século XX, em que a centralização e uma ação coordenada por mecanismos de comando, uma identidade clara e metas fortes foram 
fundamentais para o desenvolvimento do movimento. Este é o caso antes de tudo de várias expressões do movimento operário, que inspiraram em larga medida a perspectiva marxista, ou a adotaram, inclusive quando hostis a suas propostas políticas, de passagem da "classe em si" à "classe para si", levando a mobilização das coalizões locais às nacionais e alcançando amiúde a política (Marx, 1963). Uma ampliação dos horizontes do movimento acompanha seu deslocamento a níveis superiores de mobilização em planos espaço-temporais também eles mais abrangentes.

Sem dúvida, modificações importantes operaram-se dentro dos movimentos sociais ao fim do século XX e devem marcá-los no século XXI. Talvez um caráter defensivo mais acentuado deva ser esperado de alguns - embora Castells (1997:8-10, 356 e ss.) exagere ao opor fortemente "identidades de resistência", comunitárias, a "identidades de projeto", efetivamente transformadoras ${ }^{5}$. Mas é na descentralização e em grande medida no descentramento - que depende em parte daquela, implicando porém uma identidade mais ampla e frouxa, metas menos definidas ao longo do tempo, assim como da substituição dos mecanismos de "comando" pelos de "rede" - que a novidade de muitos dos novos movimentos sociais deve ser buscada. Foi isso que os trabalhos seminais de Melucci (1996), por exemplo, assinalaram. Isso deve ser explicado, creio, com apoio na tese de que os mecanismos de desencaixe têm visto sua operação se aprofundar nas últimas décadas, no que venho chamando de "terceira fase da modernidade", de "articulação mista", na qual de modo geral os mecanismos de coordenação baseados nas redes sociais (colaboração voluntária) tendem a se expandir, assumindo papel mais proeminente ao lado dos mecanismos de hierarquia (comando) e mercado (troca) (Domingues, 2002b, cap. 8). Isso decorre, ainda que fenômenos contraditórios operem também, de um certo aumento da liberdade dos sujeitos, cujas identidades se tornam mais contingentes e cujas práticas sociais são mais heterogêneas. A articulação forte dos movimentos de cima para baixo, sobretudo daqueles que tratam de temas que atravessam perpendicularmente a sociedade, se torna mais difícil. As "redes" põem-se, portanto, como solução parcial para isso.

De início isso demonstra, é claro, o quanto os movimentos sociais se enraízam na vida cotidiana dos sujeitos e coletividades e como, na verdade, seu espaço de experiência e horizonte de expectativas depende dela. Marx assinalou essa questão seguidamente, supondo 
também a homogeneidade das formas de vida básicas da classe trabalhadora, o que levaria a seu centramento como "classe em si". Thompson (1980) mostrou, por meio de sua historiografia, como isso se deu no caso da classe trabalhadora inglesa, em termos de valores, práticas e da construção de esferas públicas específicas, sendo estes os elementos que concorreram para a formação do movimento trabalhista britânico desde antes do próprio cartismo até a emergência da social-democracia inglesa em suas cores e roupagens particulares. Teóricos dos movimentos sociais, como Tarrow, assinalam, como visto acima, igualmente a questão, ao falarem, analítica e substantivamente, de como os movimentos sociais recorrem a círculos sociais externos para que se façam viáveis e possam mobilizar as pessoas. Melucci propõe o mesmo argumento, ao apontar para o caráter descentrado, heterogêneo, plural e altamente individualizado das "redes" sociais (em sentido lato) que subjazem aos novos movimentos sociais (não obstante, por vezes, forçar, para fins de ressaltar a novidade de suas teses, a oposição entre antigos e novos movimentos). Em suma, toda a literatura dos movimentos sociais, de forma consciente ou inadvertidamente, demonstrou precisamente a tese de que há uma relação direta e estreita entre a vida cotidiana e os movimentos sociais.

Os movimentos sociais globalizados ou globalizantes do período contemporâneo evidenciam exemplarmente essa articulação e como distintos espaços-tempo se imbricam enquanto dimensões de distintos sistemas sociais.

Isso se revela, primeiramente, na divisão necessária que se deve operar entre "redes transnacionais de advocacia" e "movimentos sociais transnacionais" (Keck eSikkink, 1998). Enquanto as primeiras devem ser, elas também, entendidas com base nas categorias desenvolvidas para o estudo dos movimentos sociais, por outro lado, diferem destes em muitos aspectos. Na verdade, são com freqüência alternativas à "ação de massas", cuja mobilização também amiúde tentam evitar. Fundamentalmente, elas incluem "atores relevantes trabalhando uma questão internacionalmente". Elas dependem de valores compartilhados, discursos comuns e forte intercâmbio de informações e serviços, constituindo-se em "estruturas comunicativas para a troca política", compostas de atores não-governamentais assim como de funcionários estatais e de organizações multilaterais. Embora dependam também em certa medida de redes sociais, isto é muito mais débil do que no caso de movimentos sociais, cuja base nessas redes é 
muito mais profunda e decisiva; ademais, a dificuldade de criar "quadros culturais comuns" por sobre fronteiras limita a ação dessas redes de advocacia a questões pontuais (como campanhas específicas, por exemplo, por direitos humanos ou contra a circuncisão feminina), ao contrário do cunho mais permanente e mais geral dos movimentos sociais.

Isso leva certos autores (Johnston e Laxer, 2003) a argumentarem inclusive que o sucesso dos movimentos sociais no plano global tende a depender fortemente de suas bases nacionais, implicando militância nos planos local e nacional - além de serem seus laços com o Estado nacional com freqüência relevantes. Experiências locais, práticas comuns, relações de parentesco e "profundos sentimentos de identidade e solidariedade", por um lado, e, por outro, o envolvimento de "um pequeno número de ativistas moralmente mobilizados" são aspectos decisivos para o sucesso de tais movimentos. Ademais, eles somente decolam, no plano global, se logram, na longa duração de sua mobilização, atingir uma "linguagem" mais universal para articular politicamente seus problemas. Em grande medida, aí se localizam a força e as debilidades do movimento zapatista de Chiapas, no México, e do movimento anti-MAI (Acordo Multilateral de Investimento), sobretudo no Canadá e na França.

Essa conjunção de fatores faz da constituição de movimentos sociais transnacionais ou globais uma tarefa difícil, mas não impossível. Como diz Tarrow:

“[...] identidades encaixadas em relações da vida cotidiana são com
freqüência a base de agregação em movimentos sociais, e isto é um ób-
vio obstáculo à construção de movimentos através de fronteiras naci-
onais. A tarefa de criar identidades que 'viajarão' é difícil mas não in-
trinsecamente impossível, como o exemplo do islã fundamentalista
militante mostra" (2001:12).

Em outras palavras, uma dupla direção deve ser seguida para que um tal movimento seja viável: manter seus círculos locais permanentes na vida cotidiana, na qual emergem e atuam seus militantes, e construir pontes com outros contextos, no caso globais. Dois horizontes, um mais imediato do Ser-aí, para fazer um empréstimo ao argumento de Heidegger sobre a cotidianidade, e outro mais amplo e abstrato, o global histórico, precisam ser articulados praticamente para que um movimento desse tipo logre se desenvolver. Isso já era um problema, 
é claro, ao se tratar dos movimentos nacionais, como de resto Marx percebera. Complica-se, contudo, ao atingir o plano global, porquanto não se encontrem culturas compartilhadas em princípio, e as instituições similares às do Estado nacional, que originalmente enquadravam a ação dos movimentos sociais e às quais esta era dirigida, não se achem sempre presentes no plano global. Um novo horizonte de práticas e valores deve ser portanto criado para que movimentos globais sejam efetivos, o que não é simples. Não é por acaso que mais comum seja a emergência de "redes transnacionais de advocacia", às quais muitas vezes se articulam inclusive movimentos sociais mais estritamente nacionais. Sem dúvida há aqui uma imbricação de dois âmbitos de sistemas sociais e de suas dimensões espaço-temporais. Todavia, ela se mostra mais tênue e indireta do que é o caso quando fortes movimentos sociais se articulam no plano global.

Mas é possível avançar um pouco mais nessa direção. Haveria outras formas de mobilização social para a administração da historicidade, isto é, para retomar os termos de Koselleck, para a mobilização dos espaços de experiência e dos horizontes de expectativa?

Um dos elementos constituintes da modernidade, inclusive de "seu mundo da vida" (como visto acima com Habermas), tem sido a "esfera pública", traço fundamental da vida cotidiana (como percebido por Heidegger, 1993, §§ 34-38:166-180). Essa esfera implica uma mobilização social que responde também diretamente pelo desenvolvimento histórico em termos da articulação forte dos espaços de experiência e dos horizontes de mobilização. Os processos interativos que constituem a esfera pública articulam-na como uma subjetividade coletiva que se enraíza igualmente na vida cotidiana dos indivíduos e coletividades. No modelo habermasiano a esfera pública aparece unificada e bastante centrada, abarcando todo o âmbito nacional (Habermas, 1984). Entretanto, outros modelos de esfera pública, menos centralizados, foram sugeridos, analítica e normativamente. A noção de "contrapúblicos", em sua multiplicidade, apresentou-se como uma concepção crítica ao modelo habermasiano, tendo sido pensada ainda dentro dos quadros do Estado nacional (Fraser, 1997). Mais recentemente um modelo pós-nacional descentrado, todavia, vem sendo avançado, também ele, mais implicitamente, como uma alternativa à concepção de Habermas (Eder, 2001; Costa, 2003). Primeiramente, ele foi desenhado tendo a Europa como foco, mas pode ser ampliado para outras coordenadas. Em lugar de um público centralizado ou, se 
descentralizado, no sentido de constituir contrapúblicos, porém ainda mantendo o recorte do Estado nacional, ele implica círculos de interação transversal, perpendiculares às fronteiras dos Estados, sem ademais convergirem para um foco único. Esse novo modelo pós-nacional mantém de todo modo o eixo original da teoria na articulação entre esfera pública e instituições formais estatais ou supra-estatais, passo que não deve ser tomado, creio, como necessário ${ }^{6}$.

Isso é o que se mostra bastante vividamente nas discussões sobre o Atlântico Negro encetadas por Gilroy (2000, em especial cap. 1 para sua articulação conceitual). Este surge como um espaço de trocas culturais mediado inicialmente pelos navios e portos e, depois, pela mídia. Moderno, ele inclui uma temporalidade que recupera tradições de forma plural, fornecendo uma contracultura da modernidade. Essa abordagem do espaço-tempo conformado pelo Atlântico Negro possibilita o deslocamento do modelo nacionalista de estudos culturais, em favor de uma abordagem que destaca "a estrutura risomórfica, fractal" dessa formação internacional transcultural (idem:4). Instituições formais aqui não têm papel relevante a cumprir, uma vez que é a contradição a elas ou o mero evitá-las que move essa teia supra-estatal, ainda que com freqüência a concretização de suas demandas remeta aos Estados nacionais que se incluem nesse recorte mais amplo. Se no caso das esferas públicas mais claramente definidas a ligação com a vida e os temas do cotidiano é bastante direta, o Atlântico Negro põe isto em maior evidência, seja por meio dos projetos dos intelectuais fundadores das iniciativas de redenção da "diáspora africana", e o fato de que essa perspectiva cultural era portada pelos navios - "microssistemas vivos, micropolíticos" em movimento -, seja mediante fenômenos como o hip-hop, os quais unem jovens negros ao articular seu cotidiano de forma absolutamente decisiva e direta. Isso não implica que haja, em boa parte dessas manifestações, uma tentativa de unificar os elementos que conformam a vida cotidiana nas diversas margens e geografias do Atlântico Negro, embora não se deva desconhecer projetos político-culturais que visam esse fim. O fato é que, em grande medida bastante descentradamente em termos da conformação de uma subjetividade coletiva, os espaços de experiência e os horizontes de expectativa modernos do Atlântico Negro se desenham por intermédio desses movimentos complexos no plano da cultura, nos quais se afirma uma intencionalidade difusa, baseada em identidades flutuantes e frouxas, bem como em pouca concerta- 
ção para a ação. Diversos e díspares espaços-tempo sociais imbricam-se, de formas igualmente variadas, em sua tessitura.

Aonde quero chegar com essa linha de raciocínio? Na verdade, trata-se de buscar mostrar que a história e a mudança social se articulam à vida cotidiana, para além dos processos absolutamente não-intencionais e amiúde mais localizados que caracterizam esta última, por meio de subjetividades coletivas diversas, sem que se deva privilegiar exclusivamente os movimentos sociais, sem prejuízo de sua centralidade, principalmente no que tange a transformações sociais com maior grau de intencionalidade (não obstante ser esta amiúde baldada). Níveis diversos de centramento devem ser esperados nessa articulação da história com o cotidiano, dependendo de cada sistema social e de seus processos concretos de integração. A figura abaixo procura sintetizar esse argumento:

\section{Nível de centramento}

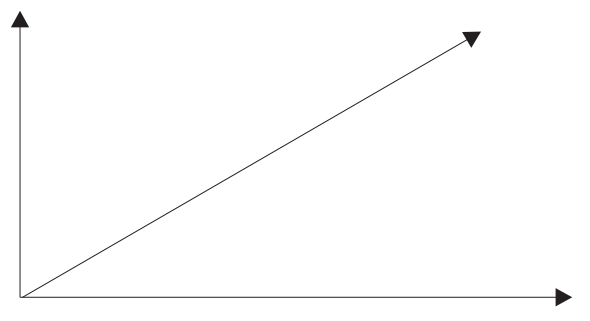

\section{Enraizamento social}

Relação com a vida cotidiana HORIZONTE

Interno

Externo

\section{Amplitude do Espaço-Tempo}

Assim, o eixo vertical da figura inclui o nível de centramento do sistema social em questão, seja ele um movimento social (de diversos tipos), uma esfera pública (de ordens distintas), um movimento mais amplo como o Atlântico Negro, ou mesmo processos mais abrangentes e descentrados (como, quem sabe, as mulheres em sua dispersão e relativa unidade na modernidade global contemporânea). O eixo horizontal da figura assinala a abrangência do sistema em questão, por exemplo, seu caráter local, nacional ou internacional. Enfim, o eixo perpendicular aponta para a profundidade relativa do enraizamento do sistema em foco na vida cotidiana. Resta ainda considerar a presença do horizonte (de expectativas - que implicitamente se deve ver como acompanhado do espaço de experiência). Ele remete, como a figura busca caracterizar, tanto à vida cotidiana quanto à historicidade mais ampla, que se define pela amplitude espaço-temporal do sistema em questão. A dimensão interna refere-se à conformação do pró- 
prio sistema, ao passo que a externa remete suas relações e a sua inserção aos universos mais amplos da cotidianidade e da historicidade.

\section{CONCLUSÃO}

O objetivo deste artigo foi analisar a relação entre cotidiano e história, buscando mostrar a continuidade entre esses dois universos e sua articulação específica. Para além da historicidade geral dos processos sociais, desde as interações mais localizadas e prosaicas, até os grandes acontecimentos, procurei analisar como movimentos sociais e outros processos sociais abrangentes articulam cotidiano e historicidade. Para tanto, introduzi o conceito fenomenológico de horizonte, que refinei com a distinção entre espaço de experiência e horizonte de expectativa; o mesmo propósito teve a introdução do conceito de subjetividade coletiva e de níveis variáveis de centramento.

Se a espécie humana é histórica por excelência, do cotidiano aos grandes processos sociais medeiam diferenças de grau importantes. As experiências e horizontes individuais e coletivos vão do mais próximo e imediato ao mais distante. Quanto mais próximo e imediato o círculo e a problemática da interação, mais densos e mais conhecidos são eles; quanto mais amplos e distantes, mais abstratos e rarefeitos tendem a ser os espaços de experiência e os horizontes de expectativa, embora o enraizamento dos sistemas mais amplos na vida cotidiana possa fazer com que essas abstração e rarefação sejam menores. O nível de centramento do sistema em si não consiste em uma variável decisiva nesse sentido, conquanto possa sê-lo, embora o movimento logre desenvolver-se somente na medida em que as relações que mantém com suas bases respeita as características destas (como sugeri acima ao introduzir a visão de Melucci dos novos movimentos sociais). Do contrário, é pouco provável que o movimento tenha sucesso, seja na dispersão que marca parcialmente as suas fases mais rotineiras, seja nos momentos que implicam grandes mobilizações.

É exatamente isso que nos permite fazer uma ponte entre o que Eder (1993:5, 48 e ss.) caracteriza como a diferença nos estudos dos movimentos sociais nas tradições européias, mais ligada a uma herança cultural-filosófica, e norte-americana, de cunho mais organizacional. Se a primeira chama a nossa atenção decisivamente para a importância dos movimentos sociais para o desenvolvimento social e para a evolução da espécie humana, a segunda possibilita que, mediante 
idéias como mobilização de recursos e enraizamento social dos movimentos, se alcance uma articulação mais precisa entre cotidiano e história. Assim, enfrenta-se o problema que assinalei, ao discutir brevemente as contribuições de Heidegger e Sartre a essa temática e seus limites. Pessoalmente, desenvolvi esse ponto ao analisar o movimento protestante, em particular nos Estados Unidos, em suas relações com a emergência do capitalismo, ao buscar, indo além de Weber, mostrar a articulação das seitas protestantes com a sociedade inclusiva. Argumentei que elas só obtiveram sucesso por ser sua flexibilidade e abertura à fragmentação um espelho do movimento de individualização e pluralização que marcava exatamente a sociedade daquele período (ver Domingues, 1995b:156-160). É isso que poderíamos observar também, por exemplo, no Movimento dos Trabalhadores Sem-Terra (MST) e sua abertura para os assalariados rurais e os desempregados urbanos, deserdados de terra e trabalho, em cujo imaginário cintila ainda a promessa da "terra em que se plantando tudo dá". Homens e mulheres livres de um Brasil moderno, "desencaixados", sua mobilidade espacial somente é possível na medida em que sua questão é menos a agrária do que aquelas que nos ficam de uma modernização avançada que, entretanto, não gerou condições e instituições capazes de incorporar essas vastas massas de trabalhadores livres (Domingues, 2002c).

Esses diversos sistemas sociais, com suas dimensões espaço-temporais peculiares, se desdobram também de forma díspar: alguns se confinam à curta duração, outros alcançam a média, outros se abrem para a longa duração. Cada uma delas é relativa também, na medida em que a curta duração inclui interações mais circunscritas e efêmeras, a média, coletividades como famílias (gerações), organizações e movimentos sociais específicos, ao passo que a longa duração varia de formações sociais específicas às grandes civilizações históricas, alcançando ao fim e ao cabo a larguíssima duração da evolução da espécie humana (ver Domingues, 1995a; 1995b, cap. 8). São essas dimensões espaço-temporais, cada uma delas com seu próprio horizonte, que costuram o próprio tecido da história.

Alguns argumentam que a concepção contemporânea da história se transformou radicalmente e que a "pós-modernidade" cancela a perspectiva de futuro (Jameson, 1991). Isso equivaleria a dizer que o horizonte de expectativas, se não desapareceu por completo da cena presente, encolheu violentamente, e que a isto corresponde por outro 
lado a avassaladora expansão do espaço de experiência moderno. Pode ser que alguma mudança tenha de fato ocorrido nessa direção, em alguns países do mundo. De modo geral, contudo, apesar de a reprodução da vida social ser em maior ou menor extensão um dos aspectos do processo histórico, creio que o signo da historicidade como mudança ainda comanda o imaginário moderno. Creio também que, desde o cotidiano em suas formas mais limitadas e prosaicas, passando por movimentos bastante descentrados e amplos, até os grandes movimentos sociais com propósitos transformadores claros, a idéia de que é possível e necessário reconstruir o mundo em que vivemos, ou ao menos certos aspectos dele, ainda desempenha e desempenhará papel crucial no desenvolvimento histórico da modernidade e na evolução da espécie humana. Nossos horizontes, apesar de tudo, mantêm-se abertos, em qualquer um dos planos que examinamos aqui - da vida cotidiana e das interações localizadas até o global e o da história em sua longa duração.

(Recebido para publicação em setembro de 2003)

\section{NOTAS}

1. Nos textos originais em alemão Erlebnis refere-se obviamente a "vivência", que as traduções para o inglês vertem como experience, portanto, com freqüência, "experiência" em traduções para o português. As duas palavras são empregadas aqui de acordo com os textos utilizados em ambas as línguas.

2. Kuhn (1940) analisa detalhadamente esse conceito em Husserl.

3. Ver minha crítica e soluções em Domingues (1999, cap. 2; 2002a).

4. Organizações, sistemas sociais altamente centrados (ver adiante), funcionam como um dos elementos fulcrais dos movimentos sociais, ao lado das redes cotidianas. "Redes", nesta literatura de movimentos sociais em geral, é um termo utilizado de forma lata, implicando círculos permanentes de interação. Seria inútil tentar modificar o termo quando esses autores o utilizam - embora eu o evite ao dar minha própria versão dessas questões. Isso é importante na medida em que tecnicamente, como se verá adiante na discussão sobre a terceira fase da modernidade, emprego o termo "rede" mais precisamente, para referir-me à coordenação da ação social por meio da "colaboração voluntária".

5. Escapa-lhe sobretudo o que chamei de "dialética da liberdade e da reflexividade", mediante a qual se poderia ver aqueles movimentos identitários defensivos como 


\section{José Maurício Domingues}

uma forma de reencaixe na modernidade que, mercê da falta de perspectiva que esta oferece, busca negar exatamente a reflexividade e a liberdade, alterando seu caráter por vezes de forma perversa (ver Domingues, 2002b).

6. Embora seja outrossim importante para entender os problemas de constituição de uma "sociedade civil" global (ver Cohen, 2003), em conjunção com aqueles que remetem aos graus diversos de inserção dos movimentos na vida cotidiana.

\section{REFERÊNCIAS BIBLIOGRÁFICAS}

ALEXANDER, Jeffrey. (1998), “Ação Coletiva, Cultura e Sociedade Civil: Secularização, Atualização, Inversão, Revisão e Deslocamento do Modelo Clássico dos Movimentos Sociais". Revista Brasileira de Ciências Sociais, vol. 13, no 37.

BORNHEIM, Gerd. (1992), Brecht. A Estética do Teatro. Rio de Janeiro, Graal.

CASTELLS, Manuel. (1997), The Power of Identity. Oxford, Blackwell.

COHEN, Jean. (2003), “Sociedade Civil e Globalização: Repensando Categorias”. Dados, vol. 46 , no 3 .

COSTA, Sérgio. (2003), “Redes Sociais e Integração Transnacional: Problemas Conceituais e um Estudo de Caso". Política E Sociedade, nำ 2 .

DOMINGUES, José Maurício. (1995a), “The Space-Time Dimension of Social Systems". Time $\mathcal{E}$ Society, vol. 4 .

. (1995b), Sociological Theory and Collective Subjectivity. London/New York, Macmillan Press/Saint Martin's Press.

(1999), Criatividade Social, Subjetividade Coletiva e a Modernidade Brasileira Contemporânea. Rio de Janeiro, Contra Capa.

(2002a), "Reflexividade, Individualismo e Modernidade". Revista Brasileira de Ciências Sociais, vol. 17, no 49 .

. (2002b), Interpretando a Modernidade. Imaginário e Instituições. Rio de Janeiro, Fundação Getulio Vargas Editora.

. (2002c), "A Dialética da Modernização Conservadora e a Nova História do Brasil". Dados, vol. 45 , no 3 .

EDER, Klaus. (1993), The New Politics of Class. London, Sage.

. (2001), "Zur Transformation nationalstaatlicher Öffentlichkeit in Europa". Berliner Journal für Soziologie, vol. 2.

FRASER, Nancy. (1997), “Rethinking the Public Sphere: A Contribution to the Critique of Actually Existing Democracies", in Justice Interruptus. Critical Reflections on the "Postsocialist" Condition. New York, Routledge. 
GADAMER, Hans-Georg. (1990) [1960], Wahrheit und Methode. Tübingen, J. C. B. Mohr.

GIDDENS, Anthony. (1987), "Erving Goffman as a Systematic Social Theorist”, in Social Theory and Modern Sociology. Cambridge, Polity.

(1990), The Consequences of Modernity. Cambridge, Polity.

GILROY, Paul. (2000) [1993], The Black Atlantic. Cambridge, MA, Harvard University Press.

GOFFMAN, Erving. (1956), The Presentation of Self in Everyday Life. Edinburgh, University of Edinburgh Press.

. (1963), Behavior in Public Places. New York, Free Press.

(1983), “The Interaction Order”. American Sociological Review, vol. 48.

HABERMAS, Jürgen. (1984) [1962], Mudança Estrutural da Esfera Pública. Rio de Janeiro, Tempo Brasileiro.

. (1988) [1981], Theorie des kommunikativen Handelns. Frankfurt am Main, Suhrkamp.

HEIDEGGER, Martin. (1993) [1927], Sein und Zeit. Tübingen, Max Niemeyer.

HELLER, Agnes. (1984) [1970], Everyday Life. London, Routledge \& Kegan Paul.

HUSSERL, Edmund. (1973) [1931], Cartesianische Meditationen. Eine Eileitung in der Phänomenomologie, in Husserliana. Hage, Martinus Nijhoff, vol. 1.

. (1964) [1939], Erfahrung und Urteil. Untersuchung zur Genealogie der Logik (3ª ed.). Hamburgo, Claassen.

JAMESON, Fredric. (1991), Postmodernism, or, the Cultural Logic of Capitalism. Durham, NC, Duke University Press.

JOHNSTON, Josée e LAXER, Gordon. (2003), "Solidarity in the Age of Globalization: Lessons from the anti-MAI and Zapatista Struggles". Theory and Society, vol. 32, no 1.

JOSEPH, Isaac. (1998), Erving Goffman et la Microsociologie. Paris, Presses Universitaires de France.

KECK, Margaret E. e SIKKINK, Kathryn. (1998), "Transnational Advocacy Networks in the Movement Society", in D. S. Meyer e S. Tarrow (orgs.), The Social Movement Society. Lanham, Rowman \& Littlefield.

KOSELLECK, Reinhart. (1985a) [1976], “'Space of Experience' and 'Horizon of Expectation': Two Historical Categories", in Futures Past. On the Semantics of Historical Time. Cambridge, MA, The MIT Press.

. (1985b) [1977], “'Neuzeit': Remarks on the Semantics of the Modern Concept of Movement", in Futures Past. On the Semantics of Historical Time. Cambridge, MA, The MIT Press.

KUHN, Helmut. (1940), "The Phenomenological Concept of Horizon", in M. Faber (org.), Philosophical Essays in Memory of E. Husserl. Cambridge, MA, Harvard University Press. 


\section{José Maurício Domingues}

LACLAU, Ernesto e MOUFFE, Chantal. (1990) [1989], Hegemony and Socialist Strategy. London, Verso.

LUHMANN, Niklas. (1991) [1971], "Die Weltgesellschaft", in Soziologische Aufklärung 2. Opladen, Westdeutscher Verlag.

MARX, Karl. (1963) [1847], Misère de la Philosophie, in K. Marx e F. Engels, Oeuvres. Paris, Gallimard, vol. 1.

MELUCCI, Alberto. (1996), Challenging Codes. Cambridge, Cambridge University Press.

MEYER, David S. e TARROW, Sidney. (1998), “A Movement Society: Contentious Politics for a New Century", in D. S. Meyer e S. Tarrow (orgs.), The Social Movement Society. Lanham, Rowman \& Littlefield.

ROCHA, Dimitri C. (2000), Divinação, Mercado e Modernidade. Tese de Mestrado, PPGSA/IFCS/UFRJ, Rio de Janeiro.

SARTRE, Jean-Paul. (1985) [1960], Critique de la Raison Dialectique. Paris, Gallimard, tomo I.

SCHUTZ, Alfred. (1967) [1932], The Phenomenology of the Social World. Eavanston, Northwestern University Press.

. (1973a) [1940], "Phenomenology and the Social Sciences", in Collected Papers. Haia, Martinus Nijhoff, vol. 1.

. (1973b) [1945], "Some Leading Concepts of Phenomenology", in Collected Papers. Haia, Martinus Nijhoff, vol. 1.

. (1973c) [1950], “Language, Language Disturbances, and the Texture of Consciousness", in Collected Papers. Haia, Martinus Nijhoff, vol. 1.

. (1973d) [1951], "Choosing among Projects of Action", in Collected Papers. Haia, Martinus Nijhoff, vol. 1.

. (1973e) [1953], "Common Sense and Scientific Interpretation of Thought Objects", in Collected Papers. Haia, Martinus Nijhoff, vol. 1.

. (1973f) [1955], "Symbol, Reality and Society", in Collected Papers. Haia, Martinus Nijhoff, vol. 1.

. (1973g) [1959], “Husserl's Importance for the Social Sciences", in Collected Papers. Haia, Martinus Nijhoff, vol. 1.

. (1975), "Some Structures of the Life-World", in Collected Papers. Haia, Martinus Nijhoff, vol. 2.

TARROW, Sidney. (1994), Power in Movement. Social Movements, Collective Action and Politics. New York, Cambridge University Press.

(2001), “Beyond Globalization: Why Creating Transnational Social Movements Is so Hard and When Is it Most Likely to Happen". Global Solidarity Dialogue (http://www.antenna.nl/ waterman/tarrow.html).

TAYLOR, Charles. (1989), Sources of the Self. Cambridge, Cambridge University Press. 
THOMPSON, Edward. (1980) [1963], The Making of the English Working Class. London, Penguin.

TOURAINE, Alain. (1984), Le Retour de l'Acteur. Paris, Fayard.

WEBER, Max. (1980) [1921-22], Wirtschaft und Gesellschaft. Tübingen, J. B. C. Mohr (Paul Siebeck).

\section{ABSTRACT \\ Daily Life, History, and Social Movements}

This article aims to discuss the relationship between daily life and history. The analysis is developed in three stages: situating the issue of daily life in one of its principal expressions in sociology; focusing on phenomenology, in particular its concept of "horizon", which I believe provides one of the keys for solving this theoretical problem; and finally seeking to relate this discussion more directly to the theoretical field of social systems, principally to the theory of social movements, since the latter have been viewed in modernity as prime inductors of historical change. The article focuses especially on the movements in this period of marked globalization, but also on the broader processes along the same lines. The theory of collective subjectivity furnishes the general underpinnings for the paper's argument.

Key words: history; daily life; horizon; social movements; collective subjectivity

\section{RÉSUMÉ}

\section{Vie Quotidienne, Histoire et Mouvements Sociaux}

Dans cet article, on discute les rapports entre vie quotidienne et Histoire. Le travail comprend trois étapes: tout d'abord, on cerne la question de la vie quotidienne à partir de l'une de ses principales expressions en sociologie. Ensuite, on recourt à la phénoménologie, en particulier à son concept d' "horizon", qui semble offrir des clés pour la compréhension de cette problématique. Et enfin on cherche à relier cette discussion au champ théorique des systèmes sociaux, en particulier à celui des mouvements sociaux, puisque ceux-ci sont vus dans la modernité comme les moteurs privilégiés du changement historique. On s'attardera non seulement sur les 
José Maurício Domingues

mouvements de notre période de mondialisation profonde mais aussi, à l'issue de cette démarche, sur des processus élargis. Les propositions de cet article se fondent sur la théorie de la subjectivité c ollective.

Mots-clé: histoire; quotidien; horizon; mouvements sociaux; subjectivité collective 